\title{
Palliative care and pediatric surgical oncology
}

\author{
Alessandro Inserra, MD, PhD ${ }^{\mathrm{a}, *}$, Alessandra Narciso, $\mathrm{MD}^{\mathrm{a}}$, Guglielmo Paolantonio, MD ${ }^{\mathrm{b}}$, \\ Raffaella Messina, $\mathrm{MD}^{\mathrm{c}}$, Alessandro Crocoli, $\mathrm{MD}^{\mathrm{a}}$ \\ a General Pediatric and Thoracic Surgery, Bambino Gesù Children's Hospital-Research Institute, Rome, Italy \\ b Interventional Radiology Unit, Bambino Gesù Children's Hospital-Research Institute, Rome, Italy

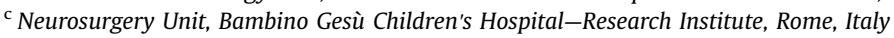

\section{A R T I C L E I N F O}

\section{Keywords:}

Pediatric palliative care

Pediatric oncology

Integrated palliative care

Cancer

Child

Interventional radiology

Radiofrequency ablation

Image-guided

Palliation

Surgical palliative care

Palliative surgery

Quality of life

\begin{abstract}
A B S T R A C T
Survival rate for childhood cancer has increased in recent years, reaching as high as $70 \%$ in developed countries compared with $54 \%$ for all cancers diagnosed in the 1980 s. In the remaining $30 \%$, progression or metastatic disease leads to death and in this framework palliative care has an outstanding role though not well settled in all its facets. In this landscape, surgery has a supportive actor role integrated with other welfare aspects from which are not severable. The definition of surgical palliation has moved from the ancient definition of noncurative surgery to a group of practices performed not to cure but to alleviate an organ dysfunction offering the best quality of life possible in all the aspects of life (pain, dysfunctions, caregivers, psychosocial, etc.). To emphasize this aspect a more modern definition has been introduced: palliative therapy in whose context is comprised not only the care assistance but also the plans of care since the onset of illness, teaching the matter to surgeons in training and share paths. Literature is very poor regarding surgical aspects specifically dedicated and all researches (PubMed, Google Scholar, and Cochrane) with various meshing terms result in a more oncologic and psychosocial effort.
\end{abstract}

(c) 2016 Elsevier Inc. All rights reserved.

\section{Introduction}

According to WHO definition, palliative care is "an approach that improves the quality of life of patients and their families facing the problem associated with life-threatening illness, through the prevention and relief of suffering by means of early identification and impeccable assessment and treatment of pain and other problems, physical, psychosocial, and spiritual."1 As a matter of fact, despite improving rate of success in diagnosis and treatment of cancer, $^{2}$ many patients experience progression of disease or recurrence and finally die of tumor, and the management of this phase of the disease is the field of palliative care. ${ }^{3}$ The term "palliative" is derived from Latin verb "palliāre" (meaning "to cover") and from substantive "pallium," which was a particular type of dress worn by ancient romans on the tunic, as a coat.

For pediatric patients, the first and most important concept is that palliative care is unique and specific and requires skills, organization, and resources, which are different from those for adults. In recent years, the developed world has seen an increase in the prevalence of incurable disease and disability. ${ }^{4,5}$ Medical and technological advances have reduced infant and child

\footnotetext{
* Corresponding author.

E-mail address: alessandro.inserra@opbg.net (A. Inserra).
}

mortality rates and, at the same time, have improved the survival rates of children with severe and potentially lethal pathologies, who need complex palliative care. ${ }^{6}$ For many years, palliative care was not offered to pediatric patients and even today in Europe, despite the development of pediatric palliative care programs in several countries, only a minority of children with incurable illness benefit from palliative care services. Many of these children will die in inadequate conditions ${ }^{7}$; without relief from distressing symptoms, usually in a hospital setting and rarely with care support in their own home where many would prefer to spend as much time as possible and eventually die. The reasons for these shortcomings in the provision of pediatric palliative care can be attributed to organizational, cultural, and economic barriers. The unique aspect of childhood illness further complicates the situation and small patient numbers, together with the multiplicity and broad geographical distribution of cases, and determines the organization of palliative care services very different to those provided for adults. Children with life-limiting and lifethreatening illnesses deserve a thorough cultural and organizational reappraisal of how we care for them when treatment is not aimed at recovery but at offering the best quality of life possible. ${ }^{8}$ In this respect, children with life-limiting and life-threatening conditions and their families have diverse and multiple needs (clinical, psychological, social, and spiritual). 
The needs of children

Physical needs:

- Symptoms control: the timely pharmacological and integrative non-pharmacological management of pain and other symptoms by appropriately skilled professionals (consequentially resulting in a reduction in the number of unnecessary hospital admissions);

- The attainment of their full potential of growth and development: these aspects must be considered and included when considering any form of treatment; and

- Advanced care planning is essential.

Psychological needs:

- Open and clear communication appropriate to the developmental stage of the child is necessary;

- Continual emotional support to help the child cope with emotive issues: understanding, acceptance, anger, self-confidence, trust, and love; and

- Access to resources and tools that promote the development of the child's personality, self-awareness (and that of others), the enhancement of individual characteristics and talents, and, where possible, the continuation of daily routines, incentives, targets, and future projects.

Social needs:

- Recreational opportunities, tools, techniques, and activities appropriate for individual needs;

- Schooling for as long and often as possible, even at home with individual tuition; and

- Social activities offering appropriate opportunities for interaction with peer groups, possibly through voluntary groups and organizations.

\section{Spiritual needs:}

- Access to appropriate spiritual care and support respecting the family's cultural and religious background.

All these individual needs are in continuous evolution, both in prevalence and intensity, directly linked to the child's psychophysical-emotional development, the phase of the illness, and its effect on growth and maturity. ${ }^{9}$

One purpose is extremely clear. As stated from the American Academy of Pediatrics, the design for pediatric palliative care services must be carefully considered, because children differ in a number of ways from adults. ${ }^{10}$ Focusing on children affected by cancer, nearly 2000 children die of a neoplasm in the United States of America annually, while about 16,000 children are expected to receive a new cancer diagnosis in the same period. ${ }^{2}$ The same figure in EU talks about 25,071 new diagnoses and 3133 expected deaths, ${ }^{11}$ while in Italy about 1500 children develop cancer every year, and about 320 of them die every year ${ }^{12}$ (population data for 2014: USA, 321 million; EU, 503 million; and Italy, 61 million).

The major categories of pediatric cancer are as follows:

Leukemia

Central nervous system (CNS)

Neuroblastoma

NHL

HL
Osteosarcoma

Ewing sarcoma

Survival for all invasive childhood cancers combined has improved markedly over the past 30 years due to new and improved treatments. The 5-year relative survival rate increased from $58 \%$ in the mid-1970s to $83 \%$ in the most recent period (20042010). However, rates vary considerably depending on cancer type, patient age, and other characteristics. The 5-year survival rate among children of age 0-14 years with retinoblastoma is $97 \%$, Hodgkin lymphoma is $97 \%$, Wilms tumor is $90 \%$, non-Hodgkin lymphoma is $88 \%$, leukemia is $85 \%$ ( $89 \%$ for lymphoid leukemia and $64 \%$ for acute myeloid leukemia), neuroblastoma is $79 \%$, Ewing sarcoma is $75 \%$, brain and other central nervous system tumors is $72 \%$; osteosarcoma is $71 \%$, and rhabdomyosarcoma is $68 \%$. Mortality rates for childhood cancer have declined by $67 \%$ over the past four decades, from 6.3 (per 100,000) in 1970 to 2.1 in 2011 and the substantial progress in reducing childhood cancer mortality is largely attributable to improvements in treatment and high rates of participation in clinical trials. ${ }^{2}$

The majority of deaths are caused by progression of initial tumor or metastatic disease and quite all patients receive palliative treatment during the last months of life, including different and/or multiple surgical procedures. In this respect, the role of surgery in palliative care is to reach if possible relief of symptoms respecting or restoring the organ function improving quality of life. Next it is possible to include in the same course prolongation of qualityadjusted and progression-free survival.

Palliation is among the most challenging tasks pediatric oncologists have to accomplish. End-of-life measures usually come after an articulated process of aggressive treatments and require a significant shift in clinical management. In this scenario, quality of life becomes the highest goal to be accomplished. ${ }^{13}$

The decision to perform a palliative surgical oncology procedure in a symptomatic patient is a frequent challenge for surgical oncologists and it requires a high level of surgical judgment and surgical expertise, and must consider the following:

(1) indications for the operation;

(2) prognosis of the disease;

(3) whether the benefits of the procedure outweigh the risks;

(4) anesthesiological risk; and

(5) do-not-resuscitate (DNR) status.

Surgical palliation should be discussed within a comprehensive multidisciplinary palliative care plan to achieve the best outcomes and maximize patient satisfaction. Surgical palliative care education should be an integral part of the surgical residency curricula and requires the development of specific competency assessment tools. Education of surgeons in training about palliative care is an emerging field. There is consensus that a competent surgeon will have a basic level of skill in meeting the needs of all of those patients with life-threatening illnesses, including the dying patient. As a matter of fact, early integration of palliative care as a standard approach for children and adolescents diagnosed with cancer carries meaningful opportunities to improve symptom control and quality of life for patients and their families. Children and adolescents living with cancer and their families should receive early, integrated access to family-centered palliative care concepts (symptom assessment and intervention; direct patient report; effective communication; and shared decision-making) to minimize symptom burden, ease suffering, effectively manage pain, and provide preventative bereavement care. The essence of all of these palliative care efforts seems to be "preservation of dignity." 14 The goal is to make palliative care "usual care" in advanced illness, also for children. 


\section{Palliative surgical procedures}

Palliative surgical procedures can be divided into the following two groups:

- Procedures with a direct influence on symptoms relief both performed as a single operation and considered as a part of multidisciplinary approach. Those interventions are necessary to control symptoms such as pain, dyspnea, fluid collection, urinary/intestinal obstruction, endocrine hypertension, and hemorrhage.

- Procedures to guide or enable administration of supportive care/ non-surgical palliative treatment, such as vascular access positioning for drugs administration, hemodialysis, and parenteral nutrition and gut intubation for feeding (PEG).

\section{Pain}

Pain is a common problem in pediatric palliative care. ${ }^{15}$ Feudtner et al. $^{16}$ in their observational cohort study reported that about $31 \%$ of more than 500 children experienced pain. Pain is frequently observed in children with cancer and usually increases in frequency with disease progression. ${ }^{15}$ It has been estimated that about $90 \%$ of terminal patients would experience pain and require medical intervention, making it the most frequent complaint in children with end-stage cancer. ${ }^{6,17-19}$ Despite a more liberal use of pain drugs, including opioids, in the past decades, about $30 \%$ of children will experience drug-resistant pain syndromes in the last stages of their lives. ${ }^{20,21}$ Most of the children with refractory pain have solid tumors $(98.4 \%){ }^{22}$ Cancer pain significantly conditions quality of life in these children. Pain surgery is still the best if not the only solution for this challenging population. Despite a growing body of evidence ${ }^{23-29}$ and the urgency of a global consensus, a standardized approach to refractory pain in children is far to be available.

\section{Intrathecal therapy}

Leptomeningeal dissemination is a possible manifestation of metastatic cancer. It is more typical of CNS tumors but it can be

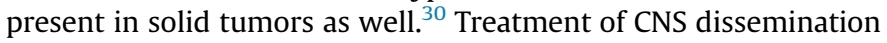
might be challenging, mainly because of limitations of drug penetrations through the blood-brain barrier. Systemic treatment to result in appropriate cerebrospinal fluid (CSF) concentrations might result in the need of high doses with intolerable side effects. The first step after systemic pharmacological treatment is usually to consider intrathecal (IT) drug infusion. Therefore, many treatment regimens include intrathecal administration of chemotherapy in the presence of CNS disease dissemination, classically through intermittent lumbar punctures. The same treatment approach might be justified in the palliative care scenario because leptomeningeal spreading of disease generally corresponds to an overall survival of 6-8 weeks that can be extended to 3-9 months by intrathecal therapy. ${ }^{31-33}$ Repeated lumbar punctures might be technically challenging and there is a reported chance of injecting in the epidural or subdural space in about $10 \%$ of the cases. ${ }^{34}$ Moreover, the discomfort of the procedure might become inappropriate for a palliative scenario. To overcome this problem, ventricular access devices that help in overcoming the bloodbrain barrier are available. They were initially developed to treat CNS infections but their use later spread to a number of different applications. ${ }^{35,36}$ In children with cancer, it can provide an easy access to the CSF compartment allowing sampling and injection of selected drugs. The device consists of an intraventricular catheter connected to a subcutaneous reservoir. ${ }^{37,38}$ Implant of the device is relatively easy, and neuronavigation can be used to allow precise catheter positioning in children with small ventricles. Puncture of the subcutaneous reservoir is easy, time saving, safe, painless, and it can be performed with platelet counts as low as $20,000 / \mathrm{mm}^{3}$. Limitations of intrathecal chemotherapy include, however, possibility of poor disease control and possibility of serious encephalopathy. ${ }^{39,40}$

Interventional radiology can play an important role in case of terminal malignancy severe pain that does not respond to massive intravenous opioid infusions through the implantation of such systems for epidural or intrathecal infusion. ${ }^{41,42}$ However, only a small number of children with cancer require neuraxial anesthesia to control their pain. ${ }^{41,43}$ Collins et al. ${ }^{44}$ referred that only $4 \%$ of children dying of cancer required epidural or intrathecal infusions to control their pain. ${ }^{41}$ The principle is based on the percutaneous positioning of a lumbar epidural or subarachnoid catheter to deliver selected drugs in direct contact to nervous tissue allowing a 100 -fold reduction of drug concentration. ${ }^{45,46}$ Technical advancements have resulted in availability not only of IT external infusion lines to be connected to infusion pumps but also of internalized systems with subcutaneous programmable infusion pumps. ${ }^{47}$ If an external infusion line is an acceptable measure for bed-ridden patients, intermittent filling of subcutaneous reservoirs might be a more convenient solution for patients experiencing invalidating pain but still able to ambulate. IT infusion of analgesics has shown a better side effects profile than systemic administration and should be considered every time there is evidence of reduced therapeutic window with systemic treatment or adverse effects become limiting on the dose administration. ${ }^{48}$ IT opioid infusion is the most studied intervention for chronic pain, firstly described in 1979. ${ }^{49}$ Later studies have documented a higher chance of pain control using IT drug infusion rather than a comprehensive systemic medical management, suggesting the superiority of the IT route. ${ }^{48}$ Current guidelines indicate IT infusion of pain medications should be considered whenever systemic treatment fails to satisfactorily control pain or it is associated to intolerable side effects including nausea, vomiting, stipsis, and urinary retention. ${ }^{50}$ Most of the experience comes from the use of opioids (morphine and hydromorphone) and other drugs (bupivacaine, clonidine, and ziconitide).

\section{Peripheral nerve block}

Children experiencing regional pain syndromes, especially in association with tumor invasion, might also be considered for intermittent or continuous peripheral nerve blocks and neurolysis. ${ }^{23,51,52}$ The choice between IT drug infusion versus nerve blocks depends on the localization of pain: abdominal, thoracic, and lumbar pain would be better treated by IT infusion, while lateralized limb pain would be a better candidate to regional nerve blocks. $^{53-55}$

For example, percutaneous imaging-guided celiac plexus neurolysis is a valid therapeutic alternative in the management of intractable abdominal pain in patients with upper abdominal malignancy ${ }^{56-59}$ (Figure 1). The multidetector computed tomography (MDCT) guidance has superseded other modalities allowing direct visualization of the spread of the neurolytic agent, such as ethanol, in the antecrural space. ${ }^{59}$ Celiac plexus neurolysis diminishes pain and helps to reduce opioid requirements and their related side effects improving survival in patients with upper abdominal malignancy. ${ }^{59}$ Cryoablation and radiofrequency ablation are less frequently used techniques in pediatric palliative care and usually considered for malignant painful lesions in the axial and appendicular skeleton and in numerous soft tissue locations. ${ }^{41,60,61}$ 

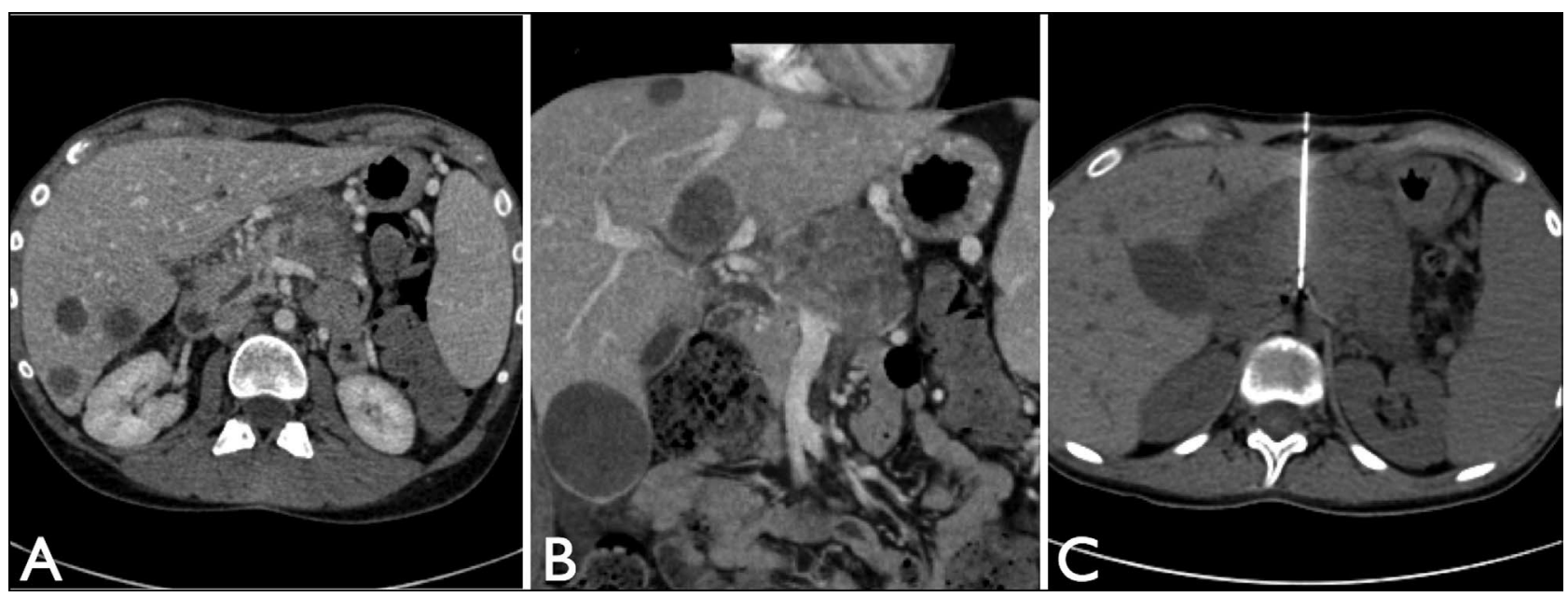

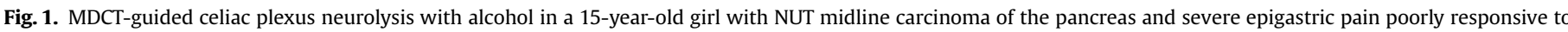

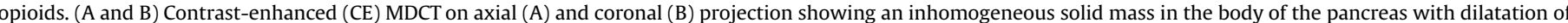

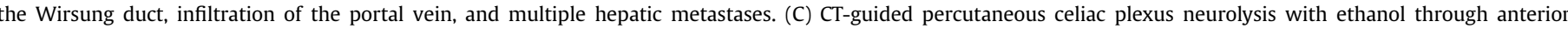

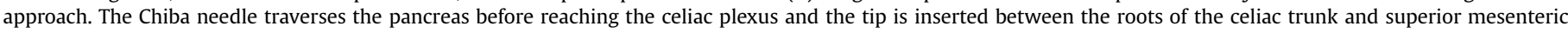
artery.

\section{Ablative surgical procedures}

Different extensive surgical procedures have been traditionally described for the treatment of non-responsive pain. The basic concept is that of surgically interrupting the nervous pathway transmitting nociception from the periphery to the thalamus and cortex. Not only miniaturization of approaches has resulted in easier and safer procedures to be performed by surgeons and anesthesiologists but also destructive surgery has been largely replaced by neuromodulation procedures. High-frequency electrical stimulation of selected nervous structures results in interference of function and is equivalent to anatomical ablation. The major advantage of neuromodulation is its reversibility but it comes at the price of very expensive equipment that might not be always indicated in the palliative care scenario.

First descriptions of cordotomy dates back to $1912^{43}$ and consisted of open surgical interruption of the spino-thalamic pathway several levels above the painful area. This procedure has now evolved in a minimally invasive percutaneous imageguided needle cordotomy. ${ }^{62-64}$ The new technique consists of inserting a needle in the upper cervical spinal cord at C1-C2 level under CT of fluoroscopic guidance in order to reach the anterolateral quadrant of the opposite side. ${ }^{65}$ After positioning has been confirmed, electrical stimulation confirms coverage of painful body areas by current-induced paresthesias coagulation of the nervous tissue at target, is performed. Indications include peripheral intractable lateralized pain. Hemiparesis and dysesthesia have become very rare with percutaneous cordotomy, and mortality is virtually absent. Further advantages are represented by short hospitalization and low costs. ${ }^{66}$ Application in children, however, has not been reported yet probably because of the need to actively participate to the procedure confirming correct positioning of the needle during intraoperative stimulation.

Midline myelotomy can be considered a variant of the cordotomy technique. It can be performed both by an open procedure through a laminotomy and by a percutaneous needle technique. Interruption of spino-thalamic fibers crossing in the midline allows bilateral control of pain making it the procedure of choice for bilateral and visceral pain. ${ }^{66,67}$

Both myelotomy and cordotomy share possible side effects depending on the lesioning of adjacent structures in the spinal cord. An alternative is represented by selective sectioning of posterior root fibers at desired levels. This procedure, named selective dorsal rhizotomy, was developed by Sindou et al. ${ }^{67}$ and evolved in a more refined procedure named DREZ that targeted the dorsal root entry zone. ${ }^{68}$

Neuroablation procedures can also target more cranial structures in the central nervous system. Mesencephalotomy aims at lesioning the pain pathway at the level of the cranial midbrain. ${ }^{69}$ The technique consists in stereotactic transcranial placement of a needle electrode and coagulation of tissue laterally to the aqueduct. More lateral lesions result in interruption of the spinothalamic way, whereas medial ones involve the spino-reticular way. Main complications include lesioning of the more anteriorly placed medial lemniscus ${ }^{70,71}$ with severe contralateral dysesthesia and impairment of ocular movements. ${ }^{72-74}$

Ablation of a number of targets in the cerebrum has also been described to contribute to intractable pain control. ${ }^{75}$ Spino-thalamic projections to ventral medial and lateral thalamic nuclei have paved the way to thalamotomy procedures. They can include stereotactic coagulation of centralis lateralis, centromedian/parafascicular, ventrocaudal, medial posterior, and posterior centrolateral nuclei. Cingulotomy has also been described to contribute to pain control, especially on the affective component of the pain experience. The target area in the anterior part of the cingulate gyrus and the procedure can be performed bilaterally with minimal postoperative neuropsychological changes including attention deficits. Successful results are similar to those of thalamotomy; however, cingulotomy can result in relief of a variety of symptoms including discomfort related to end-stage respiratory distress. Intracranial neuroablative procedures share a low (below 5\%) risk of bleeding. ${ }^{75}$

\section{Neuromodulation procedures}

Use of electricity to control pain has been reported since ancient times. Recent refinements in miniaturization have allowed the development of a wide range of stimulating devices that can be positioned percutaneously in the epidural space by anesthesiologists. If test current erogation is beneficial, a definitive implant can be positioned by insertion of a programmable electrical pulse generator such as spinal cord stimulator. However, an external pulse generator might still be the best option in the ambit of cancer palliation. There is still no clear consensus on the exact mechanism responsible of the antalgic effect of electrical stimulation; however, patients experience numbness in specific body areas depending on the location of the stimulating electrode. 
Suggested mechanisms include actions related to GABAergic neurons and adenosine. Alternative mechanisms might include modulation of central pain filters by recruitment of multimodality transmitting sensory pathways. Neuromodulation has been applied at different levels of the nervous system. Peripheral nerve electrodes are available; however, they generally require an open surgical procedure. Spinal cord stimulation (SCS) is more versatile as electrocatheters are available for percutaneous epidural positioning. ${ }^{76}$ As a general rule, stimulation devices should be positioned several levels above the entrance of dorsal roots of interest in order to ensure good coverage of painful body areas. Deep brain and motor cortex stimulation has also shown efficacy for the treatment of intractable pain.

All neuromodulation procedures share the great advantage of reversibility and personalization of treatment as stimulation intensity and frequency are adjustable parameters. Major limitations include infection risk, high costs, and invasiveness of surgical procedures to implant neuromodulation devices.

\section{Intracranial hypertension}

Intracranial hypertension is a common complication in endstage CNS tumors but might be associated to leptomeningeal dissemination of solid tumors as well. Clinical manifestations can be very debilitating, including headache, nausea, vomiting, cranial nerve palsies, and deterioration of consciousness. Moreover, if not treated, hydrocephalus can contribute to deterioration and death. The main problem in a chronic scenario is the overlapping of signs and symptoms deriving from leptomeningeal dissemination and intracranial hypertension. This is not a secondary problem as CSF diversion, more frequently in the form of ventriculo-peritoneal shunt, requires invasive surgery and exposes to hemorrhagic and infective complications not being indicated if life expectancy is too short.

If clinical judgment suggests the opportunity of CSF diversion, the possibility of peritoneal dissemination must be considered. ${ }^{77}$ Overall, despite invasiveness, ventriculo-peritoneal shunting might contribute to quality of life in carefully selected patients.

\section{Fluid collections}

Persistent ascites is rare in children and usually associated to previous surgery or congenital abnormalities of the lymphatic system in pediatric palliative care. ${ }^{41,78}$ While ultrasound (US)guided paracentesis in usually preferred in case of very short life expectancy, cuffed tunneled peritoneal catheters can be used for long-term external drainage. ${ }^{41}$ Uncommonly, a peritoneal catheter connected to a subcutaneous port may be an alternative tool for intermittent aspiration, once or twice per week, without a permanent external bag. ${ }^{41}$ Peritoneovenous (PVS) shunting, such as the Denver shunt, is a totally implanted system for continuous peritoneal drainage providing symptomatic relief and allowing prompt resumption of chemotherapy and/or radiotherapy in children with malignancy. ${ }^{78}$ However, Rahman et al. ${ }^{78}$ report that the use and outcome of PVS in children have been limited to a few cases. In the PVS, the peritoneal tube is connected to a central venous catheter by a subcutaneous pump device that contains a one-direction valve allowing the drainage of the ascites into the venous system $^{41,78}$ (Figure 2). The most frequent causes of device failure are the formations of a fibrin sheath on the venous catheter and the infections, so revision or removal procedures are often required. ${ }^{41,78}$ Malignant pleural effusion is also an unusual problem in pediatric palliative care. ${ }^{41,79}$ Repeated aspirations, pleurodesis, and insertion of pleural catheters or port devices are the most

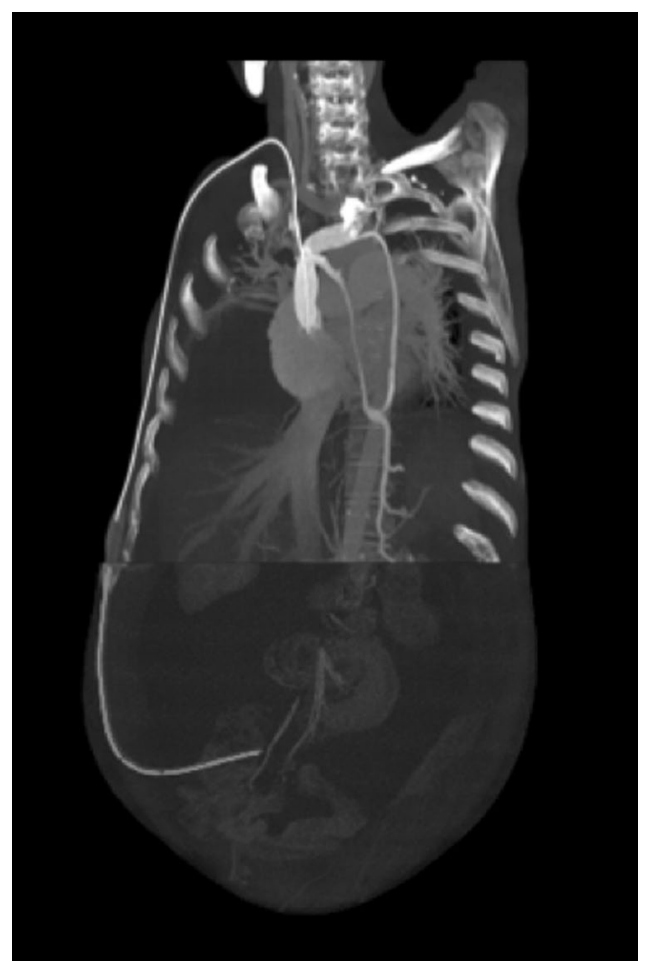

Fig. 2. PVS shunt in a girl with refractory and intractable ascites and massive right pleural effusion due to extensive abdominal lymphatic malformation. Reformatted coronal-oblique maximum intensity projection (MIP) images of thoracic and abdominal CE-MDCT shows the Denver shunt consisting of a peritoneal catheter connected to a central venous catheter by a subcutaneous valved pump chamber.

common procedures available to treat oncological children with life-limiting pleural effusions. ${ }^{41,79}$ Pleurodesis is an obliteration of the pleural space obtained through chemical agents as doxycycline and performed after US-guided insertion of a chest drain. ${ }^{41,79}$ Hoffer et al. ${ }^{79}$ report that pediatric oncology patients with intractable effusions at end of life can derive respiratory benefit from pleural drainage and pleurodeses and, as a result, are more likely to return home for terminal care. However, long-term drainage catheters or drainage port can be considered in case of failure of pleurodesis. $^{80}$

\section{Urinary complications}

Pediatric patients with advanced cancer can develop urinary obstructions. According to recent data, ${ }^{41,81}$ urinary obstruction occurs in $10 \%$ of adults with a diagnosis of advanced primary or metastatic intra-abdominal malignancy; in pediatric population, this data is not reported.

Principal cancers that may determine urinary obstruction in children are: pelvic neuroblastoma, vesical or prostatic rhabdomyosarcoma, abdominal Burkitt lymphoma or non-Hodgkin lymphoma, retroperitoneal germ cell tumors, diffuse desmoplastic tumor, and peritoneal metastatic disease. Moreover, the situation may be aggravated by periureteral fibrosis, a long-term adverse event of chemo and radiation therapy. The mechanisms of obstruction include the following: tumor growth from recurrent, metachronous, or metastatic disease; tumor blockage from extraluminal carcinomatosis, or mass; intramural growth of tumor; and direct adherence or kinking from tumor.

The symptom complex of abdominal pain, oliguria/anuria, ascites, progressive hydronephrosis, and high level of serum creatinine in children with a known cancer diagnosis is highly suggestive of urinary obstructions. ${ }^{82}$ 
Diagnostic studies include ultrasound (US) and computed tomography (CT) scans to determine the presence and level of obstruction and assess extent of cancer; magnetic resonance imaging (MRI) may be useful to detect spinal cord involvement.

The overall prognosis for this complication of cancer is poor. If early diagnosis of urinary obstruction is not done, it may develop to acute renal failure with rapid poor prognosis. Palliative care plays an important role in overall care in children with cancer. A patient is considered for receiving palliative care when he/she is not a candidate for any form of curative treatment or it is not desirable to accept the related morbidity. The goal of palliative cure is to provide comprehensive relief from disease-related or treatment-related conditions or side effects in order to achieve the highest possible quality of life and survival prolongation. Palliative cure has been shown to improve quality of life in cancer patients by addressing the harmful effects of pain and other symptoms. ${ }^{83}$

There are no guidelines for the management of malignant urinary obstruction, so the strategy depends by practice patterns between urologist and medical oncologist. ${ }^{82,84}$ The following are the options for decompression:

Open urinary diversion: Surgery is more likely to help in patients with a better prognosis, good performance status, and a single site of obstruction. Surgery options include laparotomy for tumor debulking and/or urinary tract resection with anastomosis or stoma, and suprapubic cystostomy for bladder outlet obstruction/hemorrhagic cystitis. ${ }^{85}$

Retrograde ureteral stent: Placement of a percutaneous nephrostomy tube, as an internal double J nephro-ureteric stent (double J) or as an internal/external nephroureteral stent (NUS), is the preferred initial approach in patients with limited life expectancy.

Nephrostomy tube: Percutaneous nephrostomy placement is appropriate for patients who are not candidates for an operative intervention.
Each approach can relieve the obstruction, but it is not clear if either is more or less effective. However, each intervention may cause untoward symptoms and may positively or negatively affect patient's quality of life. Specifically, the placement of nephrostomy tubes mandates the use of a leg bag for gravity drainage; double J stents and NUS may be associated with bladder irritation; and double J stents may entail potentially lengthy procedures for exchanging the stent every several months to maintain patency. ${ }^{86}$

Because these approaches are for palliation in patients who often have terminal illness, it is important to assess and compare the effect of these methods of intervention from the patient's perspective of symptom palliation and quality of life. Decisionmaking should be guided by helping patients identify concrete goals and should be individualized. Selection of therapy should consider the following: (1) the natural course and prognosis of the disease; (2) the relevance of the treatment to patients-identified goals; and (3) the experience and strengths of the management team.

Further research is needed to enable informed discussions of the risks and benefits of interventions in this population.

\section{Bowel obstruction}

In case of bowel obstruction, which is a quite common condition in children who have undergone prolonged multimodal therapies, ${ }^{87}$ symptoms are related to abnormal intestinal transit and may be a consequence of both progression of the disease (external compression of the gut by the tumor) and sequelae of treatment (multiple abdominal surgical procedures, radiation therapy, etc.). Symptoms such as abdominal distension, bilious/ fecaloid vomiting, and dehydration may determine a rapid
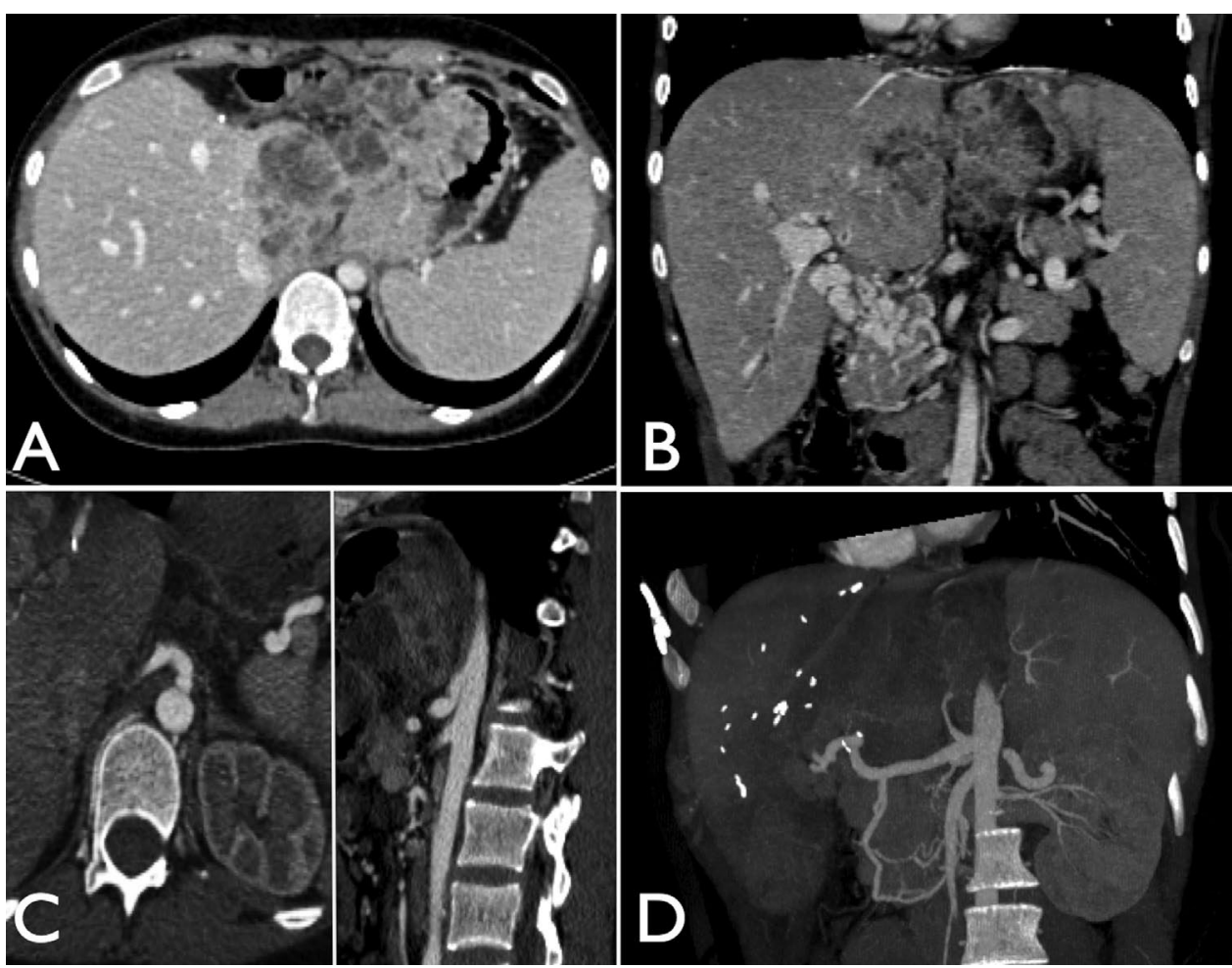

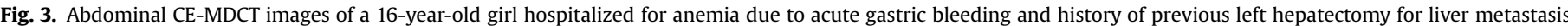

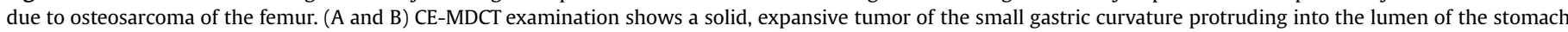

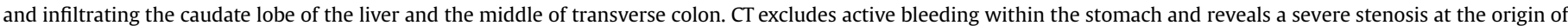
the celiac trunk with slightly post-stenotic dilatation of the common hepatic artery and revascularization by gastro-duodenal artery (C and D). 


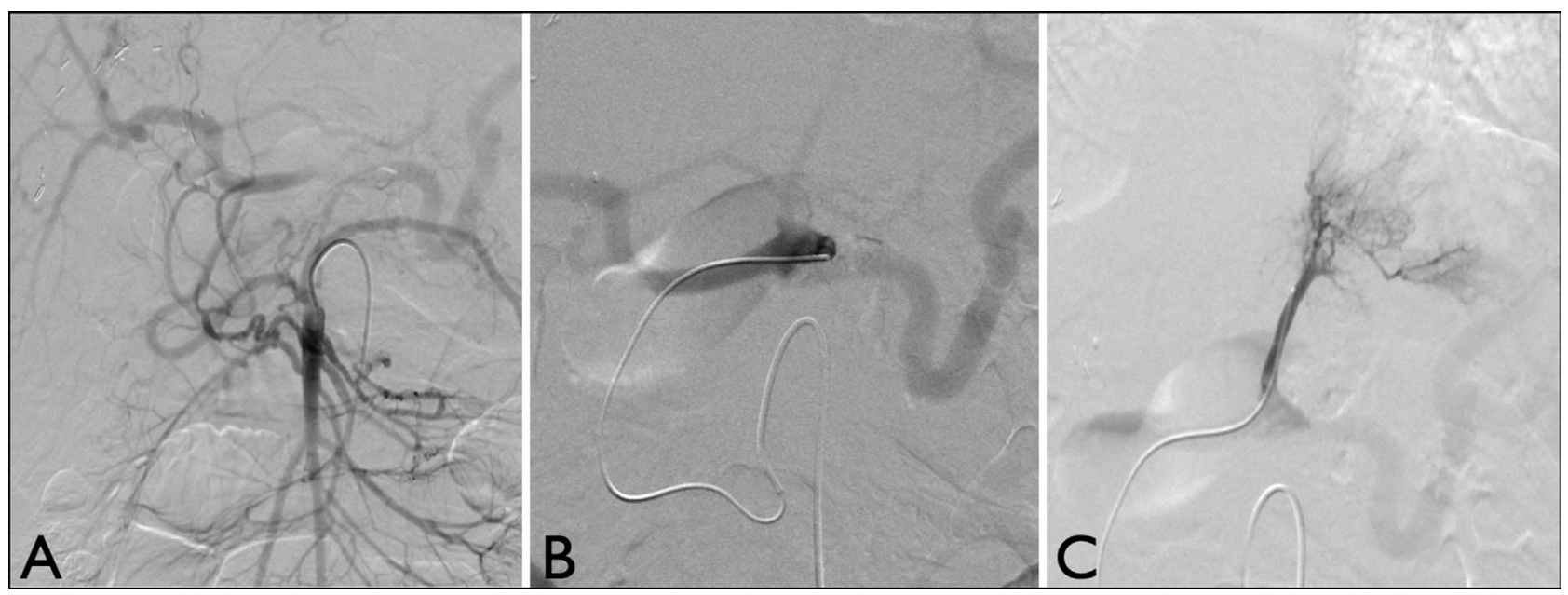

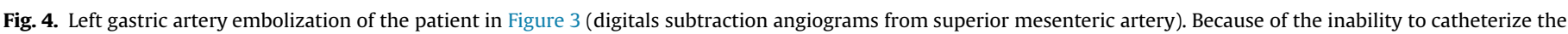

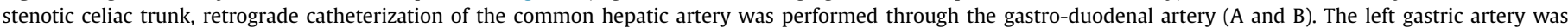
embolized using polyvinyl alcohol particles (C).

worsening of general conditions and of the performance status, thus influencing quality of life. In this respect, intestinal decompression should be considered both to relieve the patients from those symptoms and to avoid complications (dyselectrolytemia, bacterial overgrowth, and perforation). Even if an enterostoma is a disruption of normality and represent an additional trauma for parents of those children, it may give a non-negligible contribution for an improved quality of life. ${ }^{88}$ Moreover, ostomies may represent an important alternative for the nutritional requirements of patients; in this respect, gastric administration of feedings is preferred because of the ease of management, ability to use a bolus feeding regimen, and potential benefits of gastric acid as a bactericidal agent. ${ }^{89,90}$ However, jejunal placement should be considered for patients who have significant upper tract disease or when there is a high risk of aspiration, as in critically ill patients. Enteral feedings can be delivered by bolus or continuously. Bolus feedings deliver formula as rapidly as an oral feeding. ${ }^{91,92}$ This technique is simple, requires minimal supplies, and may facilitate the transition to home care. Most patients tolerate bolus feeding, but vomiting, painful abdominal distension, large gastric residuals, or diarrhea may be evidence of intolerance. When intolerance of bolus feedings is suspected, continuous infusion pump feedings are indicated. Continuous administration also is preferred for patients fed through the small intestine or at high risk of aspirating and appears to be particularly beneficial for patients suffering from impaired absorption. ${ }^{93}$
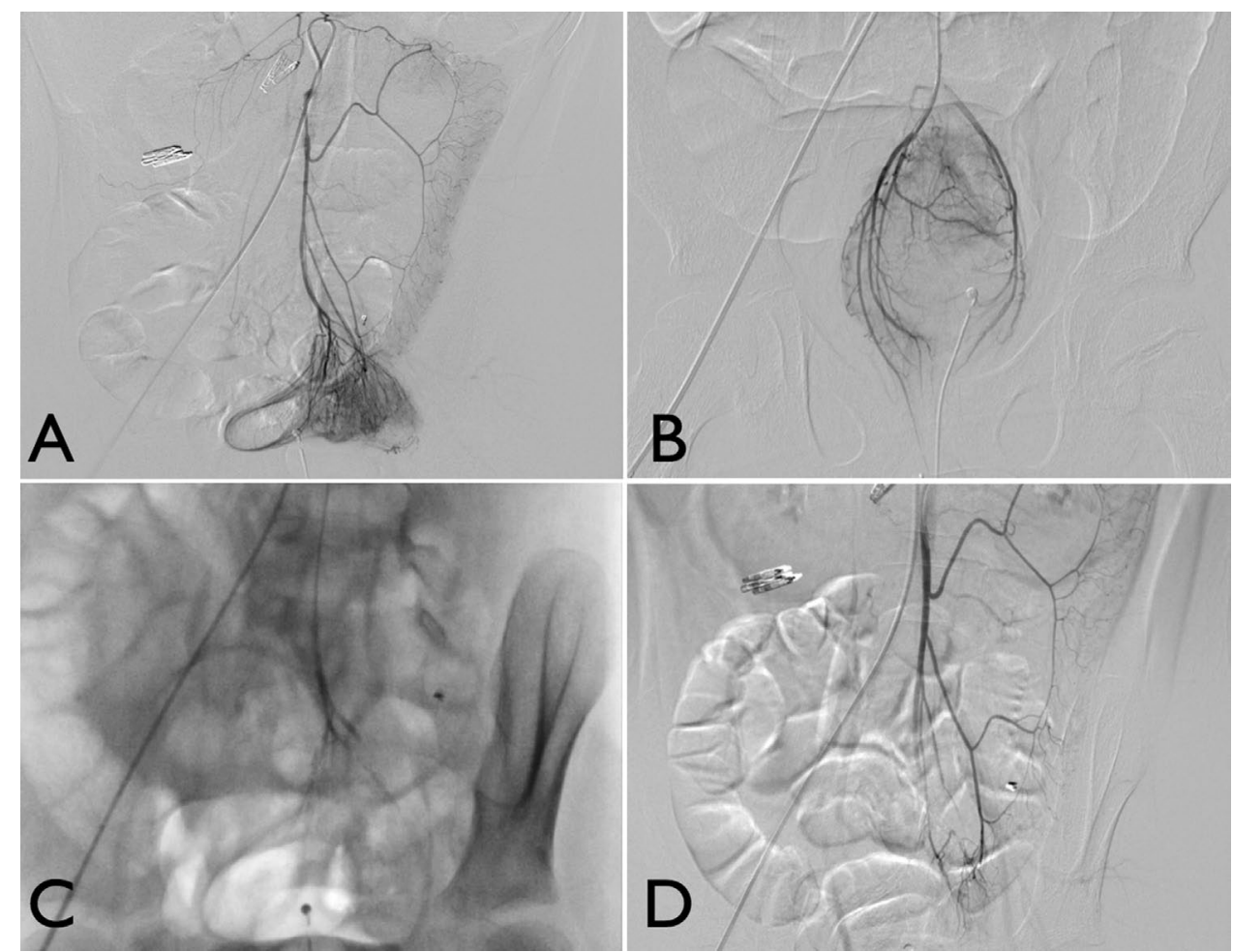

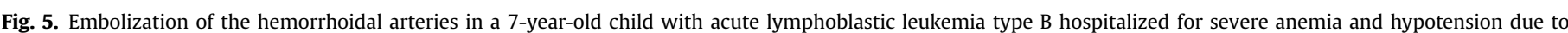

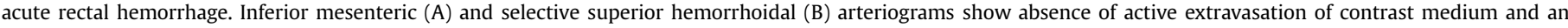

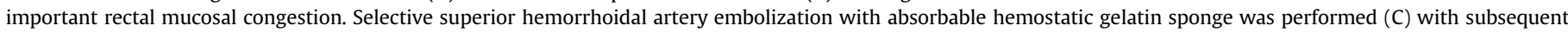
complete devascularization of the rectal wall and stopping bleeding. 


\section{Hemorrhage}

Acute internal hemorrhage is an occasionally life-threatening complication in pediatric cancer patients. ${ }^{94,95}$ Interventional radiologist is often involved in the treatment of tumor bleeding. Selective arterial embolization (SAE) is a safe and effective procedure for controlling acute intractable hemorrhage in pediatric malignancy patients ${ }^{94,95}$ (Figures 3-5). Although less usually performed in pediatric cancer patients, SAE may be preferred to surgery, which is too invasive and with attendant risks of morbidity and mortality in cancer patients with critical conditions. ${ }^{94,95}$

\section{Selective intratumoral therapies}

Moreover, interventional radiology can play an important role in the management of advanced pediatric malignancies through intra-arterial injection of chemotherapeutic or embolic agents within the lesions. Transcatheter selective arterial chemoembolization (TACE) has been suggested as an independent palliative as well as adjuvant preoperative treatment for unresectable or chemoresistant hepatoblastoma (HB). ${ }^{96-98}$ However, the optimal strategy for preoperative TACE for $\mathrm{HB}$ of infants or children remains controversial and very few reports statistically support the significant advantage of this treatment modality. ${ }^{96,97}$

Intra-arterial chemotherapy (IAC) through ophthalmic artery is considered a highly efficient treatment for advanced-stage and refractory retinoblastomas unresponsive to systemic chemotherapy $^{99,100}$ (Figure 6). IAC is a safe and high-efficacy procedure that improves globe salvage and it is expected that IAC will replace conventional strategies and will become a first-line option even for tumors amenable for other therapeutic approaches. ${ }^{99}$

\section{Conclusion}

At the present time, in most European countries, only a small percentage of children with incurable illness die at home, even if
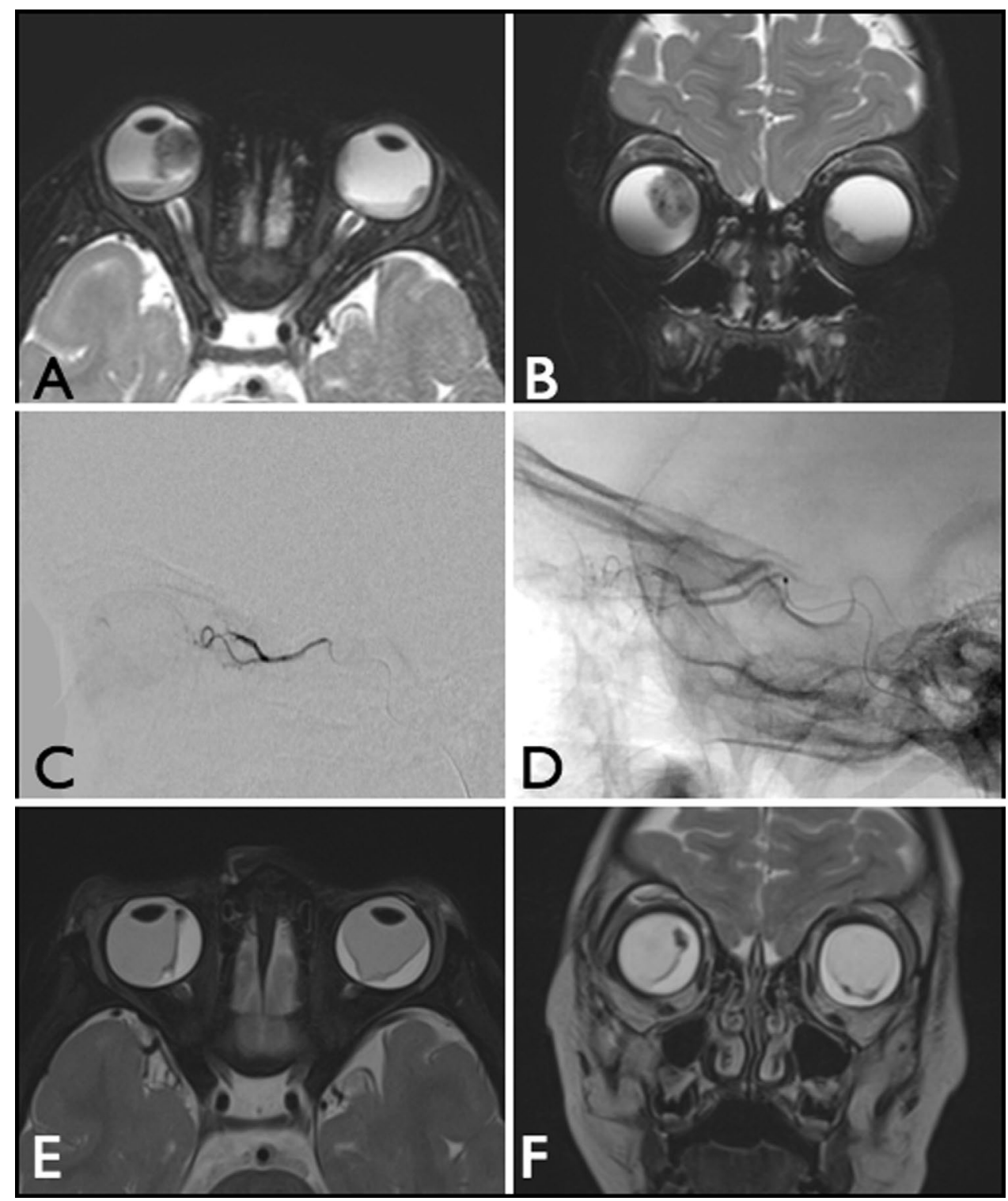

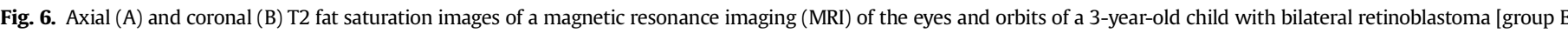

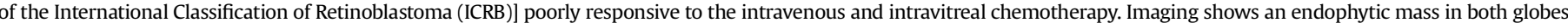

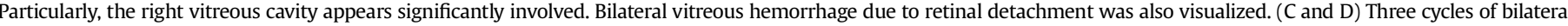

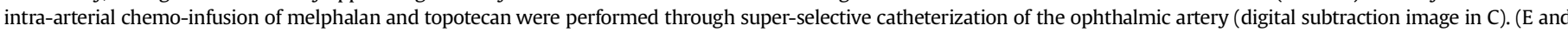

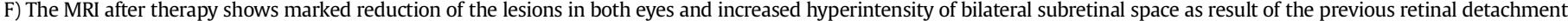


this is what most children and their parents would prefer. A large percentage of patients die in hospital, often in intensive care facilities. Furthermore, due to the lack of advanced care planning, their illness may be characterized by periods of frequent and prolonged hospitalizations, again in intensive care units or in pediatric palliative care units. Consequently, the cost of caring for these patients is relatively high, particularly during the terminal phase of their lives. The current provision of pediatric palliative care is disjointed and inconsistent, not only between countries but also from region to region in the same country, depending on the local authority's healthcare policy regarding palliative and home care services. It is, therefore, difficult to estimate the real costs of palliative care organization compared to the conventional care of these patients in hospitals. Actually, every country or even every region should collect exhaustive data regarding the costs of care for children with incurable conditions eligible for palliative care before starting a pediatric palliative care program and closely monitor spending once the program is implemented. The evaluation should include the costs of all hospital, hospice, and home care medical staff and caregivers involved in the programs, symptom management cost, and the real economic and social costs for the child and family. The costs of support for the family after the child's death should also be considered, as bereaved parents with unresolved grief can represent a high cost for society (i.e., being on sick leave). Evaluation of the quality of life, though difficult, should also be considered.

\section{References}

1. Cancer Pain Relief and Palliative Care in Children. Geneva: World Health Organization; 1998.

2. Ward E, et al. Childhood and adolescent cancer statistics, 2014. CA Cancer J Clin. 2014;64(2):83-103.

3. Goldman A, Hain R, Liben S. Oxford Textbook of Palliative Care for Children. Oxford: Oxford University Press: 2006.

4. Craig F, Abu-Saad Huijer H, Benini F, et al. IMPaCCT: standards of paediatric palliative care. Schmerz. 2008;22(4):401-408.

5. Cochrane H, Liyanage S, Nantambi R. Palliative care statistics for children and young adults. Health Care Partnerships Anal. 2007.

6. Wolfe J, Grier HE, Klar N, et al. Symptoms and suffering at the end of life in children with cancer. N Engl J Med. 2000;342(5):326-333.

7. Siden H, Miller M, Straatman L, Omesi L, Tucker T, Collins J. A report on location of death in paediatric palliative care between home, hospice and hospital. Palliat Med. 2008;22(7):831-834.

8. Kreicbergs U, Valdimarsdóttir U, Onelöv E, Björk O, Steineck G, Henter JI. Carerelated distress: a nationwide study of parents who lost their child to cancer. J Clin Oncol. 2005;23(36):9162-9171.

9. Weaver MS, Heinze KE, Bell CJ, et al. Establishing psychosocial palliative care standards for children and adolescents with cancer and their families: an integrative review. Palliat Med. 2016;30(3):212-223.

10. Feudtner $C$, et al. American Academy of Pediatrics Pediatric Palliative care and hospice care commitments, guidelines and recommendations. Pediatrics. 2013;132:966-972.

11. Kowalczyk JR, Samardakiewicz M, Pritchard-Jones K, et al. European survey on standards of care in paediatric oncology centres. Eur J Cancer. 2016;61:11-19. http://dx.doi.org/10.1016/j.ejca.2016.03.073. [Epub 2016 Apr 28]

12. Busco S, Buzzoni C, Mallone S, et al. Italian cancer figures-report 2015: the burden of rare cancers in Italy. Epidemiol Prev. 2016;40(1 suppl 2):1-120.

13. Himelstein BP, Hilden JM, Boldt AM, Weissman D. Pediatric palliative care. N Engl J Med. 2004;350(17):1752-1762.

14. Chochinov HM. Dying, dignity, and new horizons in palliative end-of-life care. CA Cancer J Clin. 2006;56(2):84-103 [quiz 104-105].

15. van den Beuken-van Everdingen MH, de Rijke JM, Kessels AG, Schouten HC, van Kleef M, Patijn J. Prevalence of pain in patients with cancer: a systematic review of the past 40 years. Ann Oncol. 2007;18(9):1437-1449.

16. Feudtner C, Kang TI, Hexem KR, et al. Pediatric palliative care patients: a prospective multicenter cohort study. Pediatrics. 2011;127(6):1094-1101.

17. Daut RL, Cleeland CS. The prevalence and severity of pain in cancer. Cancer. 1982:50(9):1913-1918.

18. Foley KM. How well is cancer pain treated? Palliat Med. 2011:25(5):398-401.

19. Maltoni M. Opioids, pain, and fear. Ann Oncol. 2008;19(1):5-7.

20. Hewitt M, Goldman A, Collins GS, Childs M, Hain R. Opioid use in palliative care of children and young people with cancer. J Pediatr. 2008:152(1):39-44.

21. Sirkiä K, Hovi L, Pouttu J, Saarinen-Pihkala UM. Pain medication during terminal care of children with cancer. J Pain Symptom Manage. 1998;15(4): $220-226$.
22. Goldman A, Hewitt M, Collins GS, Childs M, Hain R, Group UKCsCSGPONFPCW. Symptoms in children/young people with progressive malignant disease: United Kingdom Children's Cancer Study Group/Paediatric Oncology Nurses Forum survey. Pediatrics. 2006;117(6):e1179-e1186.

23. Collins JJ, Grier HE, Sethna NF, Wilder RT, Berde CB. Regional anesthesia for pain associated with terminal pediatric malignancy. Pain. 1996;65(1):63-69.

24. Aram L, Krane EJ, Kozloski LJ, Yaster M. Tunneled epidural catheters for prolonged analgesia in pediatric patients. Anesth Analg. 2001;92(6): $1432-1438$.

25. Berde CB, Fischel N, Filardi JP, Coe CS, Grier HE, Bernstein SC. Caudal epidural morphine analgesia for an infant with advanced neuroblastoma: report of a case. Pain. 1989;36(2):219-223.

26. Tsui BC, Berde CB. Caudal analgesia and anesthesia techniques in children Curr Opin Anaesthesiol. 2005;18(3):283-288.

27. Plancarte R, Patt R. Intractable upper body pain in a pediatric patient relieved with cervical epidural opioid administration. J Pain Symptom Manage. 1991;6(2): 98-99.

28. Portas M, Marty JY, Buttin C, et al. Refractory pain in children with cancer: role of peridural analgesia. Arch Pediatr. 1998;5(8):851-860.

29. Portas M, Marty JY, Buttin C. Positive effect of regional analgesia (RA) in terminal stage paediatric chondrosarcoma: a case report and the review of the literature. Pain. 1999;83(2):383-385.

30. Miralbell R, Tolnay M, Bieri S, et al. Pediatric medulloblastoma: prognostic value of p53, bcl-2, Mib-1, and microvessel density. J Neurooncol. 1999;45(2): $103-110$.

31. Berg SL, Chamberlain MC. Current treatment of leptomeningeal metastases: systemic chemotherapy, intrathecal chemotherapy and symptom management. Cancer Treat Res. 2005:125:121-146.

32. Gwak HS, Joo J, Kim S, et al. Analysis of treatment outcomes of intraventricular chemotherapy in 105 patients for leptomeningeal carcinomatosis from non-small-cell lung cancer. J Thorac Oncol. 2013;8(5):599-605.

33. Wasserstrom WR, Glass JP, Posner JB. Diagnosis and treatment of leptomeningeal metastases from solid tumors: experience with 90 patients. Cancer. 1982:49(4):759-772.

34. Chamberlain MC. Leptomeningeal metastasis. Curr Opin Neurol. 2009;22(6): 665-674.

35. Omuro AM, Lallana EC, Bilsky MH, DeAngelis LM. Ventriculoperitoneal shunt in patients with leptomeningeal metastasis. Neurology. 2005;64(9): $1625-1627$.

36. van der Ree TC, Dippel DW, Avezaat CJ, Sillevis Smitt PA, Vecht CJ, van den Bent MJ. Leptomeningeal metastasis after surgical resection of brain metastases. J Neurol Neurosurg Psychiatry. 1999;66(2):225-227.

37. Perrin RG, Lishner M, Guha A, Curtis J, Feld R, Messner H. Experience with Ommaya reservoir in 120 consecutive patients with meningeal malignancy. Can J Neurol Sci. 1990;17(2):190-192.

38. Sandberg DI, Bilsky MH, Souweidane MM, Bzdil J, Gutin PH. Ommaya reservoirs for the treatment of leptomeningeal metastases. Neurosurgery. 2000;47(1):49-54 [discussion 54-55].

39. Bokstein F, Lossos A, Siegal T. Leptomeningeal metastases from solid tumors: a comparison of two prospective series treated with and without intracerebrospinal fluid chemotherapy. Cancer. 1998;82(9):1756-1763.

40. Chowdhary S, Chamberlain M. Leptomeningeal metastases: current concepts and management guidelines. J Natl Compr Canc Netw. 2005;3(5): 693-703.

41. Roebuck DJ. Interventional radiology in paediatric palliative care. Pediat Radiol. 2014:44(1):12-17.

42. Queinnec MC, Esteve M, Vedrenne J. Positive effect of regional analgesia (RA) in terminal stage paediatric chondrosarcoma: a case report and the review of the literature. Pain. 1999;83(2):383-385.

43. Spiller W, Martin E. The treatment of persistent pain of organic origin in the lower part of the body by division of the anterolateral column of the spinal cord. J Am Med Assoc. 1912;58(20):1489-1490.

44. Collins JJ, Grier HE, Kinney HC, Berde CB. Control of severe pain in children with terminal malignancy. J Pediatr. 1995;126(4):653-657.

45. Rauck RL, Cherry D, Boyer MF, Kosek P, Dunn J, Alo K. Long-term intrathecal opioid therapy with a patient-activated, implanted delivery system for the treatment of refractory cancer pain. J Pain. 2003;4(8):441-447.

46. Sjöström S, Tamsen A, Persson MP, Hartvig P. Pharmacokinetics of intrathecal morphine and meperidine in humans. Anesthesiology. 1987;67(6):889-895.

47. Deer TR, Levy R, Prager J, et al. Polyanalgesic Consensus Conference-2012: recommendations to reduce morbidity and mortality in intrathecal drug delivery in the treatment of chronic pain. Neuromodulation. 2012;15(5): 467-482 [discussion 482].

48. Deer TR, Provenzano DA. Recommendations for reducing infection in the practice of implanting spinal cord stimulation and intrathecal drug delivery devices: a physician's playbook. Pain Physician. 2013;16(3):E125-E128.

49. Wang JK, Nauss LA, Thomas JE. Pain relief by intrathecally applied morphine in man. Anesthesiology. 1979;50(2):149-151.

50. World Health Organization. Cancer Pain Relief. Geneva: World Health Organization; 1986

51. Miser AW, Dothage JA, Wesley RA, Miser JS. The prevalence of pain in a pediatric and young adult cancer population. Pain. 1987:29(1):73-83.

52. Cooper MG, Keneally JP, Kinchington D. Continuous brachial plexus neura blockade in a child with intractable cancer pain. J Pain Symptom Manage. 1994;9(4):277-281. 
53. Baker L, Lee M, Regnard C, Crack L, Callin S, Group TS. Evolving spinal analgesia practice in palliative care. Palliat Med. 2004;18(6):507-515.

54. Coyne PJ, Smith T, Laird J, Hansen LA, Drake D. Effectively starting and titrating intrathecal analgesic therapy in patients with refractory cancer pain. Clin J Oncol Nurs. 2005;9(5):581-583.

55. Chambers WA. Nerve blocks in palliative care. Br J Anaesth. 2008;101(1): 95-100.

56. Staats PS, Kost-Byerly S. Celiac plexus blockade in a 7-year-old child with neuroblastoma. J Pain Symptom Manage. 1995;10(4):321-324.

57. Goldschneider KR, Racadio JM, Weidner NJ. Celiac plexus blockade in children using a three-dimensional fluoroscopic reconstruction technique: case reports. Reg Anesth Pain Med. 2007;32(6):510-515.

58. Carachi R, Currie JM, Steven M. New tools in the treatment of motility disorders in children. Semin Pediatr Surg. 2009;18(4):274-277.

59. Kambadakone A, Thabet A, Gervais DA, Mueller PR, Arellano RS. CT-guided celiac plexus neurolysis: a review of anatomy, indications, technique, and tips for successful treatment. Radiographics. 2011;31(6):1599-1621.

60. Hoffer FA, Daw NC, Xiong X, et al. A phase $1 /$ pilot study of radiofrequency ablation for the treatment of recurrent pediatric solid tumors. Cancer. 2009;115(6):1328-1337.

61. Lessard AM, Gilchrist J, Schaefer L, Dupuy DE. Palliation of recurrent Ewing sarcoma of the pelvis with cryoablation and somatosensory-evoked potentials. J Pediatr Hematol Oncol. 2009;31(1):18-21.

62. Kanpolat Y, Deda H, Akyar S, Bilgiç S. CT-guided percutaneous cordotomy. Acta Neurochir Suppl (Wien). 1989;46:67-68.

63. Kanpolat Y, Ugur HC, Ayten M, Elhan AH. Computed tomography-guided percutaneous cordotomy for intractable pain in malignancy. Neurosurgery. 2009;64(suppl 3):ons187-ons193 [discussion ons193-194].

64. Mullan S, Harper PV, Hekmatpanah J, Torresh H, Dobbin G. Percutaneous interruption of spinal-pain tracts by means of a Strontium 90 needle. J Neurosurg. 1963;20:931-939.

65. Hodge CJ Jr, Christensen M, Anterolateral cordotomy. In: Burchiel KJ, editor. Surgical Management of Pain. New York: Thieme; 2002. p. 732-744.

66. Raslan AM, Cetas JS, McCartney S, Burchiel KJ. Destructive procedures for control of cancer pain: the case for cordotomy. J Neurosurg. 2011;114(1): $155-170$.

67. Sindou M, Fischer G, Goutelle A, Mansuy L. Selective surgery of posterior nerve roots. First results of surgery for pain. Neurochirurgie. 1974;20(5): 391-408.

68. Nashold BS, Ostdahl RH. Dorsal root entry zone lesions for pain relief. J Neurosurg. 1979;51(1):59-69.

69. Gildenberg PL. Mesenecephalotomy for cancer pain. In: Lozano AM, Gildenberg PL, Tasker RR, editors. Textbook of Stereotactic and Functional Neurosurgery. Berlin: Springer-Verlag; 2009. p. 2533-2540.

70. Colombo F. Somatosensory-evoked potentials after mesencephalic tractotomy for pain syndromes. Neuroradiologic and clinical correlations. Surg Neurol. 1984;21(5):453-458.

71. Tasker RR. Identification of pain processing systems by electrical stimulation of the brain. Hum Neurobiol. 1982;1(4):261-272.

72. Spiegel EA, Wycis HT. Mesencephalotomy in treatment of intractable facial pain. AMA Arch Neurol Psychiatry. 1953;69(1):1-13.

73. Spiegel EA, Wycis HT. Present status of stereoencephalotomies for pain relief. Confin Neurol. 1966;27(1):7-17.

74. Amano K. Destructive central lesions for persistent paim. In: Gildenberg PL, Tasker RR, editors. Textbook of Stereotactic and Functional Neurosurgery. New York: McGraw-Hill; 1998. p. 1425-1429.

75. Steel T, Burchiel K. Neurosurgical techniques in the treatment of chronic pain. Pain: Overview. New York: Thieme; 2002.

76. Meyerson BA, Linderoth B. Mechanisms of spinal cord stimulation in neuropathic pain. Neurol Res. 2000;22(3):285-292.

77. Eralp Y, Saip P, Aydin Z, Berkman S, Topuz E. Leptomeningeal dissemination of ovarian carcinoma through a ventriculoperitoneal shunt. Gynecol Oncol. 2008; 108(1):248-250.

78. Rahman N, De Coppi P, Curry J, et al. Persistent ascites can be effectively treated by peritoneovenous shunts. J Pediatr Surg. 2011;46(2):315-319.
79. Hoffer FA, Hancock ML, Hinds PS, Oigbokie N, Rai SN, Rao B. Pleurodesis for effusions in pediatric oncology patients at end of life. Pediatr Radiol. 2007; 37(3):269-273.

80. Kriegel I, Daniel C, Falcou MC, et al. Use of a subcutaneous implantable pleural port in the management of recurrent malignant pleurisy: five-year experience based on 168 subcutaneous implantable pleural ports. J Palliat Med. 2011; 14(7):829-834.

81. Barnacle AM, Roebuck DJ, Racadio JM. Nephro-urology interventions in children. Tech Vasc Interv Radiol. 2010;13(4):229-237.

82. Rossi R, Kleta R, Ehrich JH. Renal involvement in children with malignancies Pediatr Nephrol. 1999;13(2):153-162.

83. Lambert SM. Transitional care in pediatric urology. Semin Pediatr Surg. 2015;24(2):73-78.

84. Duval M, Wood C. Treatment of non-painful symptoms in terminally ill children. Arch Pediatr. 2002;9(11):1173-1178.

85. García-Gámez A, Bermúdez Bencerrey P, Brio-Sanagustin S, et al. Vesical artery embolization in haemorrhagic cystitis in children. Cardiovasc Intervent Radiol. 2016;39(7):1066-1069. http://dx.doi.org/10.1007/s00270-016-1300-y. [Epub 2016 Feb 5].

86. Stein R, Frees S, Schröder A, et al. Radical surgery and different types of urinary diversion in patients with rhabdomyosarcoma of bladder or prostate-a single institution experience. J Pediatr Urol. 2013;9(6 Pt A):932-939.

87. Rokhsar S, Harrison EA, Shaul DB, Phillips JD. Intestinal stoma complications in immunocompromised children. J Pediatr Surg. 1999;34(12):1757-1761.

88. Parbhoo DM, Tiedemann K, Catto-Smith AG. Clinical outcome after percutaneous endoscopic gastrostomy in children with malignancies. Pediatr Blood Cancer. 2011;56(7).

89. Buderus S, Sonderkötter H, Fleischhack G, Lentze MJ. Diagnostic and therapeutic endoscopy in children and adolescents with cancer. Pediatr Hematol Oncol. 2012;29(5):450-460.

90. Fernandez-Pineda I, Sandoval JA, Jones RM, et al. Gastrostomy complications in pediatric cancer patients: a retrospective single-institution review. Pediatr Blood Cancer. 2016;63(7):1250-1253. http://dx.doi.org/10.1002/pbc.25968. [Epub 2016 Mar 9].

91. Montgomery K, Belongia M, Haddigan Mulberry M, et al. Perceptions of nutrition support in pediatric oncology patients and parents. J Pediatr Oncol Nurs. 2013;30(2):90-98.

92. Sacks N, Hwang WT, Lange BJ, et al. Proactive enteral tube feeding in pediatric patients undergoing chemotherapy. Pediatr Blood Cancer. 2014; 61(2):281-285.

93. Huhmann MB, August DA. Nutrition support in surgical oncology. Nutr Clin Pract. 2009;24(4):520-526.

94. Bae SH, Han DK, Baek HJ, et al. Selective embolization of the internal iliac arteries for the treatment of intractable hemorrhage in children with malignancies. Korean J Pediatr. 2011;54(4):169-175.

95. Hayakawa J, Ueda T, Fujiwara Y, et al. Successful coil embolization for lifethreatening hemorrhage in childhood leukemia induction therapy. Pediatr Int. 2013;55(2):248-251.

96. Hishiki T. Current therapeutic strategies for childhood hepatic tumors: surgical and interventional treatments for hepatoblastoma. Int J Clin Oncol. 2013;18(6):962-968.

97. Li JP, Chu JP, Yang JY, Chen W, Wang Y, Huang YH. Preoperative transcatheter selective arterial chemoembolization in treatment of unresectable hepatoblastoma in infants and children. Cardiovasc Intervent Radiol. 2008; 31(6): 1117-1123.

98. Tashjian DB, Moriarty KP, Courtney RA, Bean MS, Steele DA. Preoperative chemoembolization for unresectable hepatoblastoma. Pediatr Surg Int. 2002;18(2-3):187-189.

99. Zanaty M, Barros $\mathrm{G}$, Chalouhi N, et al. Update on intra-arterial chemotherapy for retinoblastoma. Scientific World J. 2014;2014:869604. http://dx.doi.org/ 10.1155/2014/869604. [Epub 2014 Oct 22].

100. Jabbour P, Chalouhi N, Tjoumakaris S, et al. Pearls and pitfalls of intraarteria chemotherapy for retinoblastoma. J Neurosurg Pediatr. 2012;10(3):175-181. 